\title{
Stygiomysis major, a New Troglobitic Mysid from Jamaica, and Extension of the Range of $S$. holthuisi to Puerto Rico (Crustacea: Mysidacea: Stygiomysidae)
}

\author{
by
}

Thomas E. BOWMAN*

The family Stygiomysidae was proposed by Caroli (1937) for an unusual new genus and species of mysid, Stygiomysis hydruntina, from caves on the Salentine Peninsula, the "heel" of the Italian "boot". Caroli gave a brief description of the male of his new mysid, stating that a more detailed study would be published later. The fuller description never appeared, however, and S. hydruntina remains inadequately characterized.

A second species, S. holthuisi (Gordon, 1958), from Devil's Hole, an anchialine sink-hole on St. Martin, Lesser Antilles, was briefly diagnosed (Gordon, 1958) and later described in full detail (Gordon, 1960).

I recently received from Dr. Stewart B. Peck, Carleton University, Ottawa, Canada, collections of Stygiomysis from Jamaica and Puerto Rico. The Jamaican specimens represent a new species, described below. The specimens from Puerto Rico are assigned for the present to $S$. holthuisi, altho they differ in a few details from Gordon's account.

\section{Stygiomysis major, new species (Figures 1-30)}

Material examined. Jamaica, Clarenden Parish (southern part, near Portland Point), Jackson Bay Cave: 2 August 1974, leg. Stewart B. Peck, of holotype (USNM 156133), and 119,4 o paratypes (USNM 156134).

Etymology. From the Latin "major", = "larger", referring to its being up to twice the length of the known species of Stygiomysis.

Description. Closely resembling Stygiomysis holthuisi, but much larger; body length of $q 9.8-20.8 \mathrm{~mm}$, of $\hat{0} 12.2-16.2 \mathrm{~mm}$ (S. holthuisi $q 9 \mathrm{~mm}$, ô $10 \mathrm{~mm}$; $S$. hydruntina $010.1 \mathrm{~mm}$ ). Telson armed as in $S$. holthuisi, but central group of terminal spines 3-5 in number, subequal in length.

Antennae with more flagellar segments than $S$. holthuisi. Antenna 1 medial

\footnotetext{
* Department of Invertebrate Zoology, Smithsonian Institution, Washington, D. C. 20560, USA.
} 


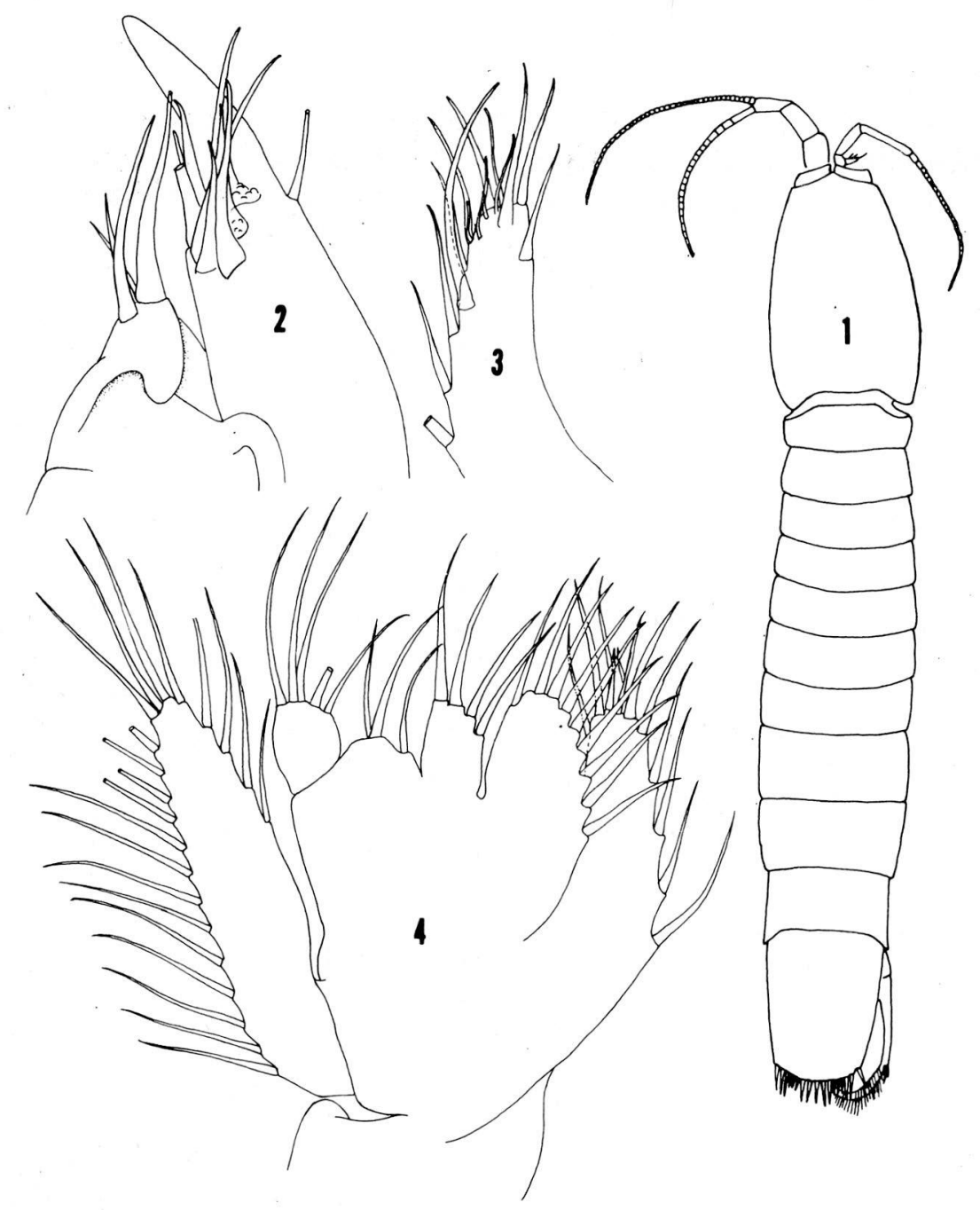

Figs. 1-4: Stygiomısis major. 1, $q$, dorsal; 2, maxilla 1; 3, maxilla 2, proximal endite; 4, maxilla 2.

and lateral flagellae with up to 49 and 31 segments respectively; antenna 2 flagellum with up to 32 segments.

Labrum with shallow emargination on anterior border. Right mandible with 4-cuspate incisor plus accessory cusp (fixed lacinia of Gordon, 1960); spine row of 7 spines. Left mandible with 3-cuspate incisor and 4-cuspate 




Figs. 5-11: St!giomysis major. 5, telson, $19.5 \mathrm{~mm} q ; 6$, telson, $11.7 \mathrm{~mm} q ; 7$, telson. $19.0 \mathrm{~mm}$ Q; 8 , uropods, ventral; 9 , left uropod, dorsal, $11.7 \mathrm{~mm} Q ; ; 10$, right antenna 1,16 $\mathrm{mm}$ ㅇ 11 , left antenna 2,16 $\mathrm{mm}$ ?;

lacinia; spine row of 8 spines. Labrum with broad, widely separated paragnaths as in $S$. holthuisi. Maxilla 1 with armature as in $S$. holthuisi; inner lobe with 2 slender and 2 robust spines; outer lobe with very stout terminal spine flanked laterally by a seta and medially by 8 slender spines. Maxilla 2, proximal endite with 10 long spines and 5 shorter setae; distal endite divided into lobes with 9 and 4 marginal spines; proximal and distal segments of endopod with 3 and 5 spines respectively; exopod with 21 marginal setae, 4 of them on medial margin (medial margin bare in $S$. holthuisi).

Maxilliped (1st thoracic leg) like that of $S$. holthuisi, with only minor differences in setation. Pereopod 1 (2nd thoracic leg) as in $S$. holthuisi, but terminal 


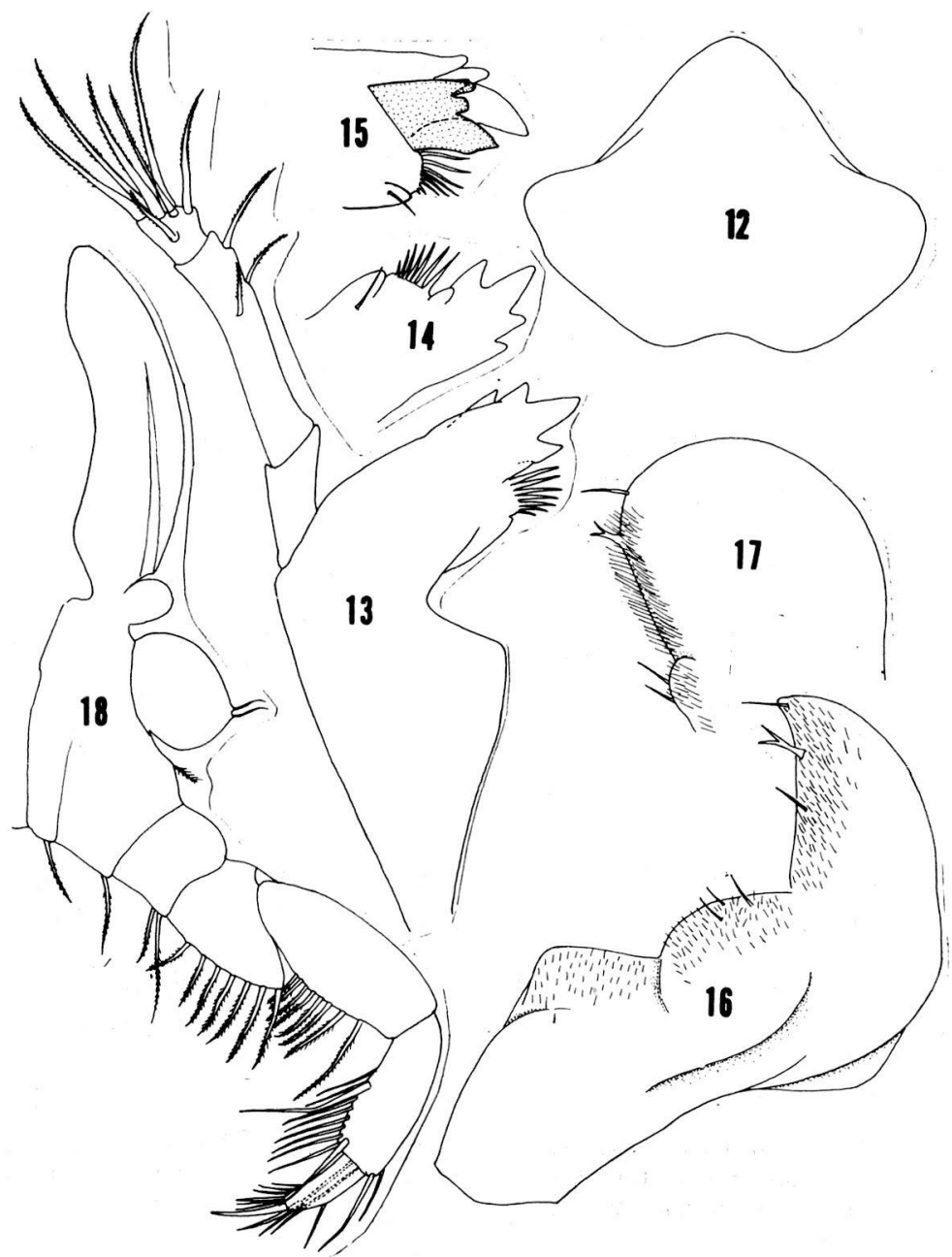

Figs. 12-18: St!giom!sis major, $16 \mathrm{~mm} q .12$, labrum; 13, right mandible; 14. rigit mandible, gnathal surface; 15 , left mandible, gnathal surface; 16, labium (half): $1 \%$. paragnath, semilateral view; 18 , right maxilliped. 


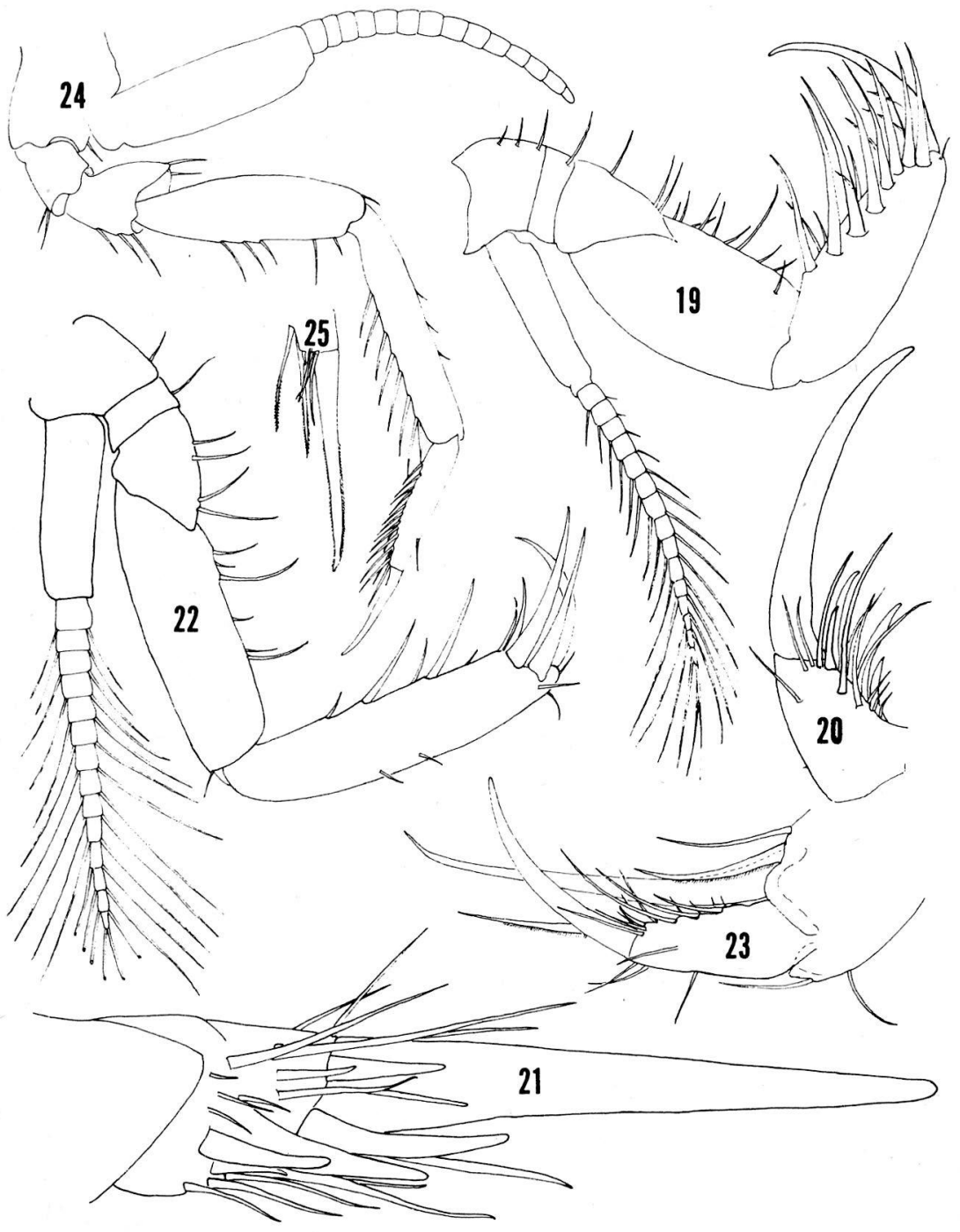

Figs. 19-25: Stygiomysis major. $16 \mathrm{~mm} q$. 19, right pereopod 1; 20, right pereopod 1, dactyl, lateral; 21, same, flexor margin; 22, right pereopod 3; 23, same, dactyl; 24, right pereopod $7 ; 25$, same, dactyl. 


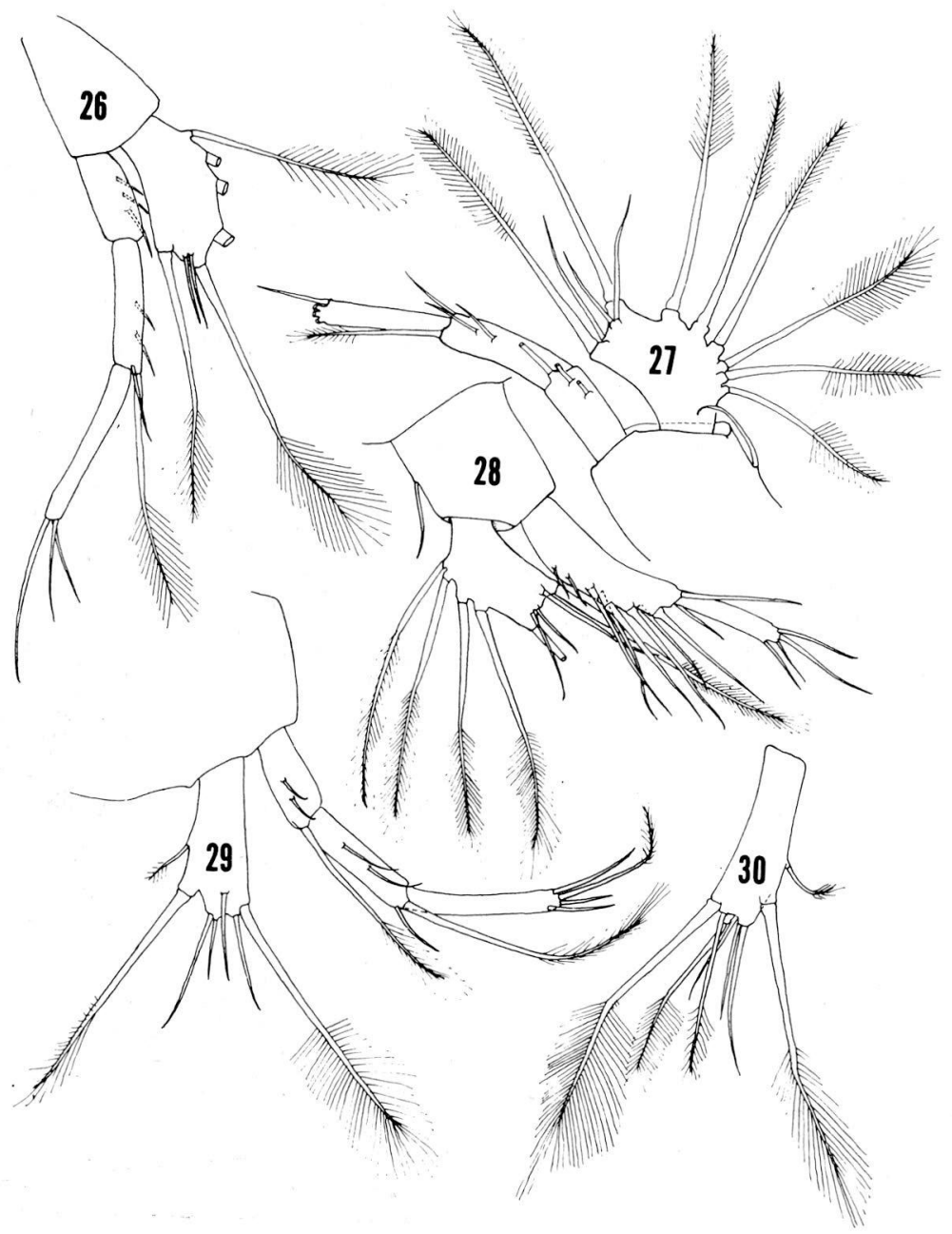

Figs. 26-30: Stygiomysis major, $16 \mathrm{~mm}$ ㅇ (except 28). 26, left pleopod 1; 27, pleopod 2; 28, $\widehat{\delta}$ pleopod 2; 29, left pleopod 3; 30, endopod of pleopod 5 .

claw longer than body of dactyl. Pereopod 3, larger of pair of spines arising from distal margin of propus extending beyond dactyl. Pereopod 7 as in $S$. holthuisi, but with more spines on anterior margins of propus and dactyl.

Pleopods with 1-segmented endopods and 3-segmented exopods, except 2 -segmented exopod of $\delta$ pleopod 2. Setae more numerous than in $S$. holthuisi. Patterns of setation as in figs. 26-30; that of pleopod 4 (not shown) same as pleopod 3 (Fig. 29).

Protopodal process of uropod with nearly straight lateral margin. Apical 


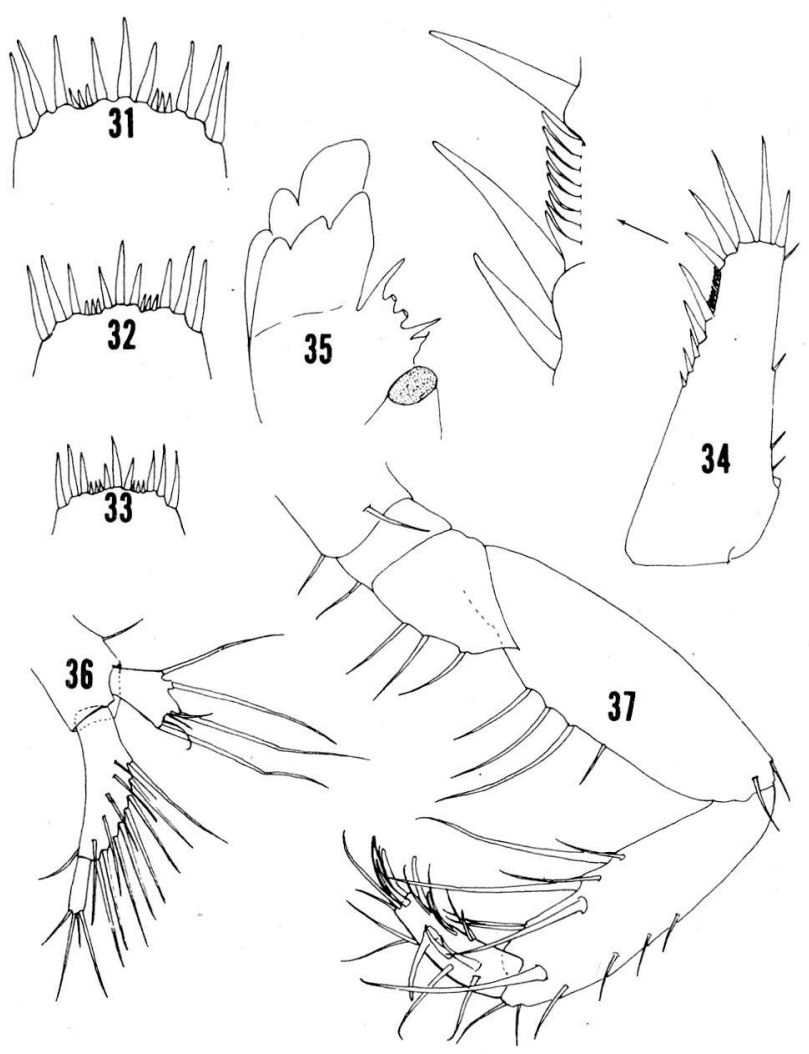

Figs. 30-35: Stygiom!sis holthuisi, from Puerto Rico. 31-33, telsons of $7.2 \mathrm{~mm} \hat{\delta} .6 .3 \mathrm{~mm} \hat{\delta_{\lambda}}$, and $4.8 \mathrm{~mm} q ; 34$, protopodal process, $7.2 \mathrm{~mm} \hat{\delta} ; 35$, left mandible. $7.2 \mathrm{~mm} \hat{\delta} ; 36$, right pleopod $2,7.2 \mathrm{~mm} \hat{\delta}: 37$, left pereopod 3 , medial, $7.7 \mathrm{~mm} \hat{\delta}$.

spines continued on medial margin by series of spines decreasing in size anteriorly, separated from apical spines by few spinules.

Relationships. Stygiomysis major is similar in most respects to $S$. holthuisi, but differs in its larger size, in the armature of the telson and uropods, and in details of the mandible, maxilla 2, pereopods, and pleopods, given in the above description. $S$. hydruntina differs in the armature of the protopodal process of the uropod and in the long spines on the dactyl of pereopod 1, which exceed the claw in length. 
Distribution. At present known only from its type-locality, Jackson Bay Cave (or Jackson's Bay Great Cave). The cave has 5 entrances and consists of a series of chambers with connecting passages (Ashcroft, 1959). Other crustaceans collected by Dr. Peck in this cave include a new species of the mysidacean genus Antromysis (Bowman, in press), the amphipod Hadzia jamaicae Holsinger (1974), and the brachyuran crab Cardisoma guanhumi Latreille (identified by Horton H. Hobbs, Jr.).

\section{Stygiomysis holthuisi (Gordon) (Figures 31-37)}

Rhopalonurus holthuisi Gordon, 1958, p. 1552.

Stygiomysis holthuisi(Gordon). - Gordon, 1960, pp. 287-324, figs. 1-18, 23-24, pl. 3.

Material examined. Puerto Rico, Guánica State Forest: Cueva Murcielagos, collected by S. and J. Peck, 12-14 VI 1974: 2 of of (7.2 and $6.3 \mathrm{~mm}), 1$ q without oostegites $(4.8 \mathrm{~mm})$. - Guánica Forest Cave, collected by B. Beck and R. Graham, III 1974: 1 ô $(7.7 \mathrm{~mm})$.

Gordon's detailed and well illustrated account of this species, until now known only from a sink-hole on St. Martin, Lesser Antilles, makes the identification of the Puerto Rican specimens relatively simple. The latter show good agreement with Gordon's account with respect to the characters that appear to distinguish $S$. holthuisi from the Jamaican species. The Puerto Rican specimens are somewhat smaller $(4.8-7.7 \mathrm{~mm})$ than the type-specimens $(9-10$ $\mathrm{mm}$ ) and have fewer flagellar segments on the 1 st and 2 nd antennae. The number of flagellar segments increases with increasing body length. The spine row of the mandible contains 5 spines. In the left mandible the incisor and lacinia are both 3-cuspate; the subsidiary tooth of the incisor found by Gordon in the right mandible was lacking in the left mandible of the Puerto Rican specimen. The distal spines of the propus are shorter than the dactyl in pereopod 3. The modified male pleopod 2 (Fig. 36) matches closely that of the male from St. Martin. The armature of the medial margin of the posterior process of the uropodal protopod appears to be the most significant difference between the St. Martin and Puerto Rico specimens. In the former this margin has "a row of spinules interrupted by one or two spines". In the latter, the distal part of the margin has a row of 8 spinules which is much more compact than the row of 5,6 , or 8 spinules shown in this position in Gordon's figs. 8 and 13. Proximal to the spinule row, the margin bears several spines diminishing in size successively. No additional proximal spinules are present as they are in the St. Martin types.

It can be argued that the protopod armature justifies recognition of the Puerto Rico specimens as a distinct species or subspecies. But until enough material is available to assess adequately the variability of $S$. holthuisi, I choose to defer judgment and, for the time being at least, to consider the Puerto Rican and St. Martin specimens to be conspecific.

In the Puerto Rican specimens, as in those from St. Martin, the median 
group of telsonic spines consists of a longer central spine flanked by 2 shorter spines.

\section{SUMMARY}

Stygiomysis major, new species, the third species of the genus, is described from Jackson Bay Cave, Jamaica. It is up to twice the length of the other known species. S. holthuisi, until now known only from its type-locality in St. Martin, is reported from 2 caves in Guánica State Forest, Puerto Rico. It differs slightly from St. Martin specimens in the armature of the uropods.

\section{RÉSUMÉ}

Stygiomysis major, nouvelle espèce, la troisième du genre, est décrite de la grotte de Jackson Bay, à la Jamaïque. Sa taille atteint le double de celle des autres espèces connues. S. holthuisi, qui n'était jusqu'alors connue que dans sa station-type de l'île St-Martin, est signalée dans deux grottes de la Guanica State Forest à Porto-Rico. Elle diffère légèrement des spécimens de St-Martin par l'armature de ses uropodes.

\section{REFERENCES}

Ashcroft, Michael, 1969. Caves of Jamaica. Jamaica Journal (Quarterly of the Institute of Jamaica), 3 (2): 32-36.

Bowman, Thomas E. (in press). A review of the genus Antromlsis (Crustacea: Mysidacea), including a new species from Jamaica and a redescription and new records for A. cenotensis. Spec. Publ. Mus. Texas Tech Univ.

Caroli, Enesto. 1937. Strgiomisis hidruntina n.g., n.sp., Misidaceo cavernicolo di Terra d'Ôtranto, rappresentante di una nuova famiglia. Nota preliminare. Boll. Zool. Torino, 8 (5-6): 219-227.

Gordon, Isabella. 1958. A new subterranean crustacean from the West Indies. Nature, 181: 1552-1553.

1960. On a Stıgiomysis from the West Indies, with a note on Spelaeogriphus (Crustacea, Peracarida). Bull. British Mus. (Nat. Hist.), Zool., 6 (5): 283-324, pls. 3-4.

Holsinger, John R. 1974. A new cavernicolous amphipod crustacean of the genus Hadzia (Gammaridae) from Jamaica, with notes on the distribution and taxonomic status of the genus. Ann. Spéléol., 29 (4): 647-655. 